\title{
ANÁLISIS DE LOS MODELOS DE VINCULACIÓN DEL CÓDIGO CIVIL Y LA LEGISLACIÓN DE PROTECCIÓN AL CONSUMIDOR. HACIA UN PRINCIPIO GENERAL DE PROTECCIÓN DE LA PARTE DÉBIL EN EL DERECHO PRIVADO
}

\author{
ANALYSIS OF THE INTEGRATION MODELS BETWEEN THE CIVIL \\ CODE AND CONSUMER LAW. TOWARDS A GENERAL PRINCIPLE OF \\ PROTECTION OF WEAKER PARTIES ON PRIVATE LAW
}

\section{RODRigo MOMBerg U.*}

\begin{abstract}
RESUMEN: El objetivo del trabajo es exponer los diversos modelos de vinculación normativa que pueden existir entre el derecho privado común, generalmente contenido en los códigos civiles, y la normativa de protección a los consumidores, con especial énfasis en materia contractual. Se plantea como mejor alternativa para dicha vinculación la integración de los principios y normas básicas de protección al consumidor al Código Civil, sin perjuicio de la existencia de legislación especial de consumo que detalle y desarrolle tales principios. El trabajo además examina la posibilidad de ampliar la protección del derecho privado más allá del consumidor, hacia un sistema que contemple la protección general de la parte débil.
\end{abstract}

Palabras clave: Código Civil - Derecho del consumidor - Protección de la parte débil

ABSTRACT: The purpose of the paper is to analyse the possible models for the normative relation between general private law and consumer law, particularly with regard to contract law. It is proposed that the best alternative is the integration of the principles and basic rules of consumer law into the Civil Code, without prejudice of the existence of specific legislation that detail and develop those principles. In addition, the paper examines the possibility to extend the protection of private law beyond the consumer, towards a development of a system that provides the general protection of weaker parties.

Key words: Civil Code, Consumer Law - Protection of weaker parties

\footnotetext{
PhD, Universidad de Utrecht. Profesor de Derecho Privado, Escuela de Derecho, Pontificia Universidad Católica de Valparaíso. Visiting Research Fellow, Instituto de Derecho Europeo y Comparado, Universidad de Oxford. Dirección postal: Av. Brasil 2950, Valparaíso. Correo electrónico: rodrigo.momberg@pucv.cl

Este trabajo se enmarca en el Proyecto Redes Cooperación Internacional, REDES 130097, Concurso de apoyo a la formación de redes internacionales, Conicyt. Agradezco los comentarios de Arturo Ibáñez y Alberto Pino a versiones previas de este trabajo, así como las observaciones efectuadas por los pares evaluadores, que sin duda ayudaron a mejorar su versión final.
} 


\section{INTRODUCCIÓN}

Desde hace un tiempo, han quedado de manifiesto los problemas que presenta la coexistencia de regímenes normativos en materia de contratación civil, mercantil y de los consumidores. Entre los inconvenientes que dicha coexistencia presenta, se pueden mencionar problemas de seguridad jurídica, como por ejemplo, la falta de certeza para los contratantes del estatuto que será aplicado a su relación jurídica; o de carácter terminológico, en que conceptos legales son utilizados de manera diversa o contradictoria. Así por ejemplo, la jurisprudencia no ha sido uniforme en la extensión que debe darse al concepto de consumidor, considerando como tal en algunas oportunidades al consumidor material ${ }^{1}$, pero negándole dicha calidad en otros fallos ${ }^{2}$. En cuanto a las inconsistencias terminológicas, basta mencionar la definición legal de la Ley 19.496 sobre Protección de los Derechos de los Consumidores (LPC) para el concepto de "oferta" (art. 1 No. 8), la cual poco tiene que ver con el significado que tradicionalmente se le otorga en derecho privado ${ }^{3}$. Incluso la falta de coordinación entre el régimen común y el del consumidor, puede implicar que paradójicamente el consumidor quede en algunas situaciones más desprotegido que el contratante particular. Así por ejemplo sucederá si se le niega al consumidor la posibilidad de recurrir a las acciones edilicias del Código Civil (CC) una vez prescritas las acciones que al efecto le concede el art. 20) de la LPC.

Por otra parte, determinar con precisión la posición formal del derecho del consumidor en el sistema jurídico no es irrelevante, ya que como se explicará, influye en la forma en que sus normas son interpretadas y aplicadas por la doctrina y los tribunales.

En este trabajo se ofrece una visión general de la cuestión, sin entrar a los detalles de cada situación de conflicto, tratando de establecer la mejor alternativa para la vinculación del derecho privado común, contenido en las tradiciones de derecho continental en los códigos civiles, y el aplicable a la regulación de las relaciones de consumo.

Este tema conserva vigencia, ya que aun cuando podría sostenerse que el derecho del consumidor cuenta con una madurez y un desarrollo doctrinario suficiente, su posición formal frente al derecho común en el sistema jurídico sigue siendo incierta. Una breve referencia a lo que sucede en distintos ordenamientos jurídicos confirma lo dicho, demostrando que se está lejos de la uniformidad en esta materia.

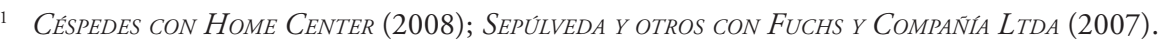

2 RAMÍrez CON VIÑA del MAR Store (2008); VASQUEZ CON SKARTOUR LIMITAdA (2008).

3 La situación es más confusa ya que el examen de la normativa contenida en al LPC permite concluir que en otros supuestos contemplados en dicha ley, el término "oferta" conserva su significado tradicional (Véase p. ej. los arts. 3 bis letra b, 12A, 32 inciso 2 y 53B).

4 Al efecto, véase BARRIENTOS (2014) y CAPRILE (2008), quien plantea la compleja situación que conlleva la existencia del cúmulo de acciones disponibles para el comprador insatisfecho: las que le confiere la ley 19.496, las edilicias, las derivadas del error sustancial y la de resolución por incumplimiento.
} 


\section{MODELOS DE VINCULACIÓN. LA SITUACIÓN EN EL DERECHO POSITIVO}

En los párrafos siguientes se presenta una referencia a la posición del derecho del consumidor en algunos ordenamientos jurídicos de Latinoamérica y Europa.

\subsection{LATINOAMÉRICA}

En Latinoamérica predomina la existencia de estatutos legales especiales en materia de protección al consumidor. Se trata de las denominadas "leyes generales de protección a los consumidores”. Así sucede en Argentina (Ley 24.240 de Defensa del Consumidor), Chile (Ley 19.496 sobre Protección de los Derechos de los Consumidores) y Colombia (Ley 1480 sobre Estatuto del Consumidor). La regla general es que no se haga referencia a la materia en los códigos civiles de tales países, sin perjuicio que otras normativas especiales puedan también aplicarse a las relaciones de consumo. La excepción la constituye el recién promulgado Código Civil y Comercial argentino, el cual contiene un Título especial que regula algunos aspectos de los contratos de consumo 5 . En otros países, la legislación especial en materia de protección del consumidor se encuentra codificada. Tal es la situación en Brasil (Código de Defensa del Consumidor) y Perú (Código de Protección y Defensa del Consumidor). En todo caso, la idea general es la misma: se trata de regular las relaciones de consumo separadamente, al margen del derecho común, y de, fundamentalmente, el CC.

\subsection{EUROPA}

En Europa, a nivel de derechos nacionales, se puede observar una gran variedad en relación a las técnicas de regulación, lo cual no deja de ser sorprendente, ya que en teoría el derecho del consumidor es quizás, a nivel de derecho privado, la rama en que el legislador europeo ha desplegado mayor actividad, con el objeto de lograr un régimen legislativo armonizado o incluso unificado.

Así por ejemplo, Alemania y Holanda han optado por incorporar a sus Códigos Civiles gran parte de la normativa general y especial en materia de contratos de consumo ${ }^{6}$. En el caso de Austria, se ha incorporado a su CC la normativa sobre cláusulas abusivas.

Otros países, quizás la mayoría, han optado por leyes generales de protección al consumidor. Así sucede por ejemplo en los casos de España ${ }^{7}$, Austria ${ }^{8}$, Portugal ${ }^{9}$ y Grecia $^{10}$.

5 Título III del Libro Tercero del Código Civil y Comercial de la Nación, aprobado por ley 26.994 y promulgado según decreto 1795/2014.

6 En el caso alemán, subsiste como legislación especial la normativa referida a productos defectuosos. Además, no existe un título especial dedicado al derecho del consumidor, sino que las normas se encuentran dispersas en el Código. Micklitz (2013) pp. 267-268, resalta que el proceso fue impulsado por la necesidad de adecuarse a la legislación de la UE, y no por razones estrictamente jurídicas o técnicas, asignándole por tanto un carácter tecnocrático.

7 Texto refundido de la Ley General para la Defensa de los Consumidores y Usuarios y otras leyes complementarias (Real Decreto Legislativo 1/2007).

8 Ley Federal de protección a los consumidores (Konsumentenschutzgesetz).

9 Ley de Defensa del Consumidor (Lei de Defesa do Consumidor, n. ${ }^{\circ} 24 / 96$, de 31 de Julio)

10 Ley de Protección a los Consumidores (ley 2251/1994). 
Ello no obsta a que también exista legislación especial para determinadas materias, por ejemplo, crédito al consumo, paquetes turísticos y tiempo compartido.

El caso del Reino Unido es interesante. Ante la necesidad de implementar la normativa de la UE sobre protección al consumidor, se había optado por la promulgación de numerosa legislación especial, entre otras, la Consumer Protection Act 1987, la Unfair Terms in Consumer Contracts Regulations 1999 y la Consumer Credit (Disclosure of Information) Regulations 2002. Con el objeto de clarificar y simplificar la legislación vigente, se promulgó recientemente la Consumer Rights Act 2015, la cual entró en vigencia el 1 de octubre de 2015. Este instrumento ha sido calificado como un verdadero código de consumo británico, ya que refunde la normativa contenida en los más importantes instrumentos legales y administrativos vigentes a la fecha ${ }^{11}$.

Por último, otros han optado por la técnica de la codificación, en su sentido estricto de sistematización de diversos instrumentos legislativos en un solo cuerpo legal. Así sucede por ejemplo en Francia (Code de la consommation) y más recientemente en Italia (Codice del consumo $)^{12}$.

\subsection{INSTRUMENTOS DE DERECHO UNIFORME}

En el caso de los instrumentos de derecho uniforme o codificaciones doctrinales, puede observarse que desde un modelo más bien limitado, destinado a regular exclusivamente la contratación comercial, se ha avanzado hacia un modelo en el que se incluye, implícita o expresamente, la contratación de consumo. Así, como expresión del primer modelo, se puede observar que tanto en la Convención de Viena sobre Compraventa Internacional de Mercaderías (CISG por sus siglas en inglés) como en los Principios UNIDROIT sobre contratos Internacionales (PICC), los contratos de consumo se encuentran excluidos por la propia naturaleza de tales instrumentos. Incluso el artículo 2 a) de la CISG expresamente excluye del ámbito de aplicación de la Convención a las compraventas de mercaderías adquiridas para uso personal, familiar o doméstico.

Por otra parte, y como expresión del nuevo modelo, cabe mencionar que los Principios Europeos de Derecho de los Contratos (PECL) se entienden aplicables a todo tipo de contratos, por lo que su normativa debería también ser aplicable a una relación de consumo, aun cuando expresamente no se refieran a ellas. Es interesante destacar que los PECL incorporan instituciones surgidas en el derecho del consumidor, haciéndolas aplicables a todo tipo de contrato. Así sucede por ejemplo con las cláusulas abusivas (art. 4:110). Asimismo, debe recalcarse la inclusión de la institución del "beneficio excesivo o ventaja injusta" (art. 4:109), también denominado "abuso de posición dominante", como un reflejo de la protección general de la parte débil.

El Borrador de Marco Común de Referencia (Draft Common Frame of Reference - DCFR), uno de cuyos propósitos fue servir como base para la elaboración de futuro instrumento facultativo en materia de derecho de contratos, avanza un paso más e incluye ex-

\footnotetext{
11 Detalles de la reforma pueden consultarse en CÁmARA LAPUente (2015) y Riefa (2015).

12 Los arts. 38 del Codice del Consumo y 1469 bis del Codice Civile establecen expresamente el carácter de derecho supletorio de este último para la contratación de consumo.
} 
presamente al consumidor y a los contratos de consumo. Al igual que los PECL, establece como de aplicación general instituciones nacidas en el ámbito del derecho del consumidor, aun cuando en ocasiones establece diversos requisitos para su aplicabilidad a cada categoría. Así sucede por ejemplo con los deberes precontractuales de información (arts. 3:101 y siguientes, Libro II), y las cláusulas abusivas (sección 4 Capitulo IX Libro II).

Por último, la propuesta sobre Reglamento para una Normativa Común de Compraventa Europea (Common European Sales Law - CESL), ha sido expresamente diseñada para regular la contratación con consumidores y destacablemente, incorpora a las Pymes como sujetos de la normativa protectora.

\section{CLASIFICACIÓN DE LOS MODELOS DE VINCULACIÓN. MODELOS DE DISTINCIÓN Y DE INTEGRACIÓN}

La descripción del derecho positivo recién efectuada permite clasificar a los modelos de vinculación entre el derecho común y el derecho del consumidor en modelos de distinción y modelos de integración.

\subsection{Modelos De DisTinción}

Los modelos de distinción siempre implican la existencia de legislación especial de consumo, separada del Código Civil, sin que este contemple ni se refiera al consumidor o a los actos de consumo. A su vez, esta legislación especial puede materializarse en diversas leyes especiales (como hasta recientemente el caso del Reino Unido) o una ley general o código (como en Chile o Brasil). Es interesante destacar que en el caso de Brasil, la dictación del CC de 2002 no supuso una derogación tácita ni expresa del Código de Defensa del Consumidor de 1990, el cual continúa vigente como ley especial para las relaciones de consumo. A diferencia de lo que ocurrió en Alemania en virtud de la reforma al BGB del año 2000, no se produjo una integración de la normativa de protección del consumidor al CC, lo que ha llevado a que la doctrina brasilera desarrolle la denominada doctrina del "diálogo de fuentes", para coordinar ambos cuerpos normativos y superar eventuales contradicciones entre ellos ${ }^{13}$.

Hay que señalar que la existencia de una ley general o código de defensa del consumidor no excluye necesariamente la existencia de otras normativas particulares que puedan aplicarse a los consumidores, pero que sin embargo no están formuladas específicamente como una regulación protectora sino como un estatuto regulatorio de un sector o actividad económica en particular. Así sucede por ejemplo con la legislación reguladora de la libre competencia, o la que regula actividades o servicios de interés público, aun cuando sean ejecutadas por privados, como sucede por ejemplo con el suministro de electricidad o de agua potable.

Por último, debe también destacarse que la normativa civil (y a veces la comercial) se mantiene expresa o tácitamente, como derecho supletorio. Así por ejemplo, el Código de Protección y Defensa del Consumidor peruano señala en su art. 45, respecto a los contratos

13 Véase Lima Marques (2011). 
de consumo, que en todo lo no previsto en dicho Código serán de aplicación las normas del Código Civil. La misma regla se establece en el Texto refundido de la Ley General para la Defensa de los Consumidores y Usuarios española (art. 59.2, que menciona también a la legislación mercantil). La norma peruana, sin embargo, hace una precisión importante: la normativa civil será aplicable cuando resulte compatible con la naturaleza de los contratos de consumo, cuestión relevante, según se expondrá en los párrafos siguientes.

\subsection{MOdelos De inTEGRACión}

Los modelos de integración implican que la normativa del consumo se encuentra, en mayor o menor medida, incorporada formalmente en el cuerpo normativo del derecho común, el cual generalmente será, en los sistemas de derecho continental, el Código Civil ${ }^{14}$. Existen aquí varias alternativas:

a) Trasposición completa del derecho (privado) de consumo contractual al CC. Así sucede por ejemplo en Holanda y Alemania ${ }^{15}$.

b) Incorporación o trasposición parcial (p. ej. solo compraventa de consumo), como en el caso de Austria.

c) Integración de conceptos y reglas generales del derecho de consumo al CC; los cuales se articulan de manera coherente con el sistema del CC.

En general, puede decirse que los modelos señalados en las letras a) y b), si bien más fáciles de implementar (basta la inserción de las normas en el CC y quizás una remuneración del articulado) presentan mayores desventajas desde el punto de vista técnico jurídico y de coherencia con el sistema interno del código. Se trata de cuerpos extraños a las bases dogmáticas del CC, las que, al menos en su formulación clásica, se fundan en el principio de la igualdad de los contratantes. En estricto rigor, en dichos casos la diferencia con los modelos de distinción es solo formal, ya que la incorporación de las normas de consumo al código se hace sin adecuarlas al sistema general o conceptual del mismo. Mantienen por tanto su especialidad y diferenciación, solo que están formalmente en un mismo instrumento normativo.

La tercera alternativa en cambio implica un verdadero trabajo de integración. La legislación especial de consumo subsiste, pero en el CC se incluyen los principios o las normas básicas del derecho del consumo, integradas de manera coherente en el sistema conceptual del derecho común. Las características y ventajas de este modelo se desarrollan más adelante en este trabajo.

A partir de la descripción de los distintos modelos de vinculación, surge la interrogante de cuál de ellos es la mejor opción. Sin embargo, antes de resolver dicha cuestión, debe plantearse una previa: ¡es posible integrar al derecho común las normas sobre derecho del consumidor?

14 Albiez (2003) pp. 145-146

15 Como se dijo, en el caso alemán con la excepción de las normas sobre productos defectuosos. 


\section{LA INTEGRACIÓN DEL DERECHO DEL CONSUMIDOR AL DERECHO PRIVADO COMÚN: SU FACTIBILIDAD TEÓRICA}

¿Es posible integrar normas del derecho de consumo en el derecho privado común contemplado en el Código Civil?

Esta pregunta se relaciona con la cuestión si en el derecho contemporáneo debe mantenerse un cuerpo de normas comunes a todo contrato o bien debería distinguirse según el tipo o categoría contractual, de manera que cada categoría tenga una estructura normativa que responda adecuadamente a sus propias características. Ello se ha discutido especialmente en el ámbito del common law, donde el tema se ha planteado en términos si debe existir un derecho contractual (law of contract) o un derecho de los contratos (law of contracts $)^{16}$.

En este sentido, la fragmentación de la regulación de las categorías contractuales (p.ej. contratos de trabajo, de arrendamiento, de consumo) plantea la cuestión de si tales categorías reflejan excepciones o calificaciones del principio de libertad contractual, o si más bien la existencia de tales categorías no hacen sino demostrar que dicho principio y sus derivados simplemente no les son aplicables, debiendo reconocerse que ciertas categorías contractuales tienen un carácter intervencionista y regulatorio ${ }^{17}$. En cierto sentido, la última alternativa supondría descartar la existencia de principios generales de derecho contractual (o al menos su relevancia), y reconocer que cada categoría contractual se encuentra regida por principios propios.

La doctrina no tiene una opinión uniforme en esta materia. Un lugar común es sostener que el derecho del consumo responde a una lógica y a principios (incluso elevados al carácter de "filosóficos") distintos del derecho de contratos plasmado en los códigos. Existirían dicotomías difíciles o imposibles de salvar, las cuales están dadas por los extremos que representan las ideas de autonomía y solidaridad, individualismo y altruismo, y la promoción del mercado y la protección o bienestar (welfarism) del consumidor ${ }^{18}$. En el mismo sentido, se ha señalado que el derecho común y el derecho del consumo difieren esencialmente, ya que la dinámica del derecho del consumidor (sujeto a cambios legislativos constantes, por razones políticas y sociales, entre otras) no se puede reconciliar con la estabilidad propia del $\mathrm{CC}^{19}$.

Sin embargo, estas diferencias, cuya existencia aparece como clara y categórica a primera vista, se vuelven difusas en un examen más profundo. Así por ejemplo, la protección otorgada al consumidor por medio de deberes de información puede conectarse (y generalmente así se justifica) con la finalidad de garantizar su autonomía al momento de decidir si contratar o no, es decir, se basa en la misma justificación que se utiliza para la contratación clásica o comercial. Lo mismo sucede con la sanción a las cláusulas abusivas, la cual en-

\footnotetext{
16 Howells y Wheaterill (2005) pp. 20, 21.

17 Howells y Wheaterill (2005) p. 31.

18 Wilhelmsson (2007) pp. 28-29.

19 Micklitz (2013) pp. 269 y 270.
} 
cuentra su justificación en el principio de buena fe, principio que es reconocido, en mayor o menor medida, en el derecho de contratos en general.

Existe (o puede existir) entonces una comunicación natural entre el derecho de contratos general y el derecho de consumidor, sin que pueda plantearse una división tajante. Se trataría más bien una cuestión de gradualidad entre los extremos de autonomía y la libertad contractual y los de la protección y la solidaridad ${ }^{20}$.

La incorporación de figuras o instituciones destinadas a la protección de la parte débil en codificaciones modernas y especialmente, en instrumentos internacionales de derecho contractual, demuestra que es posible integrar normas protectoras y al mismo tiempo mantener los principios de autonomía individual y libertad contractual, los cuales por cierto son interpretados y calificados a la luz de esta normativa protectora. Quizás el ejemplo más evidente, e importante, es el reconocimiento del abuso de posición dominante, también denominado beneficio excesivo, ventaja injusta o explotación injusta (arts. 3.2.7 PICC, 4:109 PECL, 7:207 DCFR y 51 CESL) ${ }^{21}$. Esta figura esencialmente sanciona los beneficios o ventajas excesivos que se generan para una parte con la celebración del contrato, por el aprovechamiento de la situación de desventaja económica, social o moral de la otra. Los comentarios de los PECL y el DCFR dejan claro que se trata de una excepción a la fuerza obligatoria del contrato, y por tanto de aplicación restringida ${ }^{22}$. Para que opere se requiere que 1) una de las partes se encuentre en una situación de desventaja, 2) que la otra se aproveche a sabiendas, o no pudiendo menos que saber, de dicha desventaja, y 3) que se produzca para ella un beneficio excesivo o una ventaja notablemente injusta con la celebración del contrato. Si se cumplen los requisitos, tanto la parte afectada como la aventajada pueden solicitar al juez que adapte el contrato según lo que se hubiera acordado en caso de haberse respetado las exigencias de la buena fe y la lealtad comercial al momento de contratar.

\footnotetext{
20 Hesselink (2014) p. 34, habla del mito de asignar a priori un carácter liberal a los CC que no necesariamente tienen. Ello es especialmente cierto respecto de los CC del siglo XX y XXI.

21 A modo de ejemplo, el art. 7:207 del DCFR dispone que: "Explotación injusta: (1) Cualquiera de las partes puede impugnar el contrato si en el momento de conclusión del mismo: a) Era dependiente o tenía una relación de confianza con la otra parte, se encontraba en situación de dificultad económica o ante necesidades acuciantes, era poco previsor, ignorante, carente de experiencia o poco apto para la contratación. b) La otra parte conocía o debía haber conocido tales circunstancias y dadas estas y la finalidad del contrato, se aprovechó de la situación de la primera de las partes en forma gravemente desleal u obtuvo un beneficio excesivo. (2) A requerimiento de la parte facultada para impugnar, el tribunal puede, si ello es apropiado, adaptar el contrato para ponerlo en concordancia con lo que las partes hubieran convenido si hubieran cumplido las exigencias de la buena fe y la lealtad. (3) Igualmente el tribunal puede adaptar el contrato a requerimiento de la parte a quien se ha notificado la pretensión de impugnación por beneficio excesivo o ventaja desleal, siempre que esta parte informe de ello a la otra prontamente tras haber recibido la notificación y antes de que dicha parte actuara confiando en ella."

22 DCFR Full Edition (2010) p. 507.
} 


\section{LA INTEGRACIÓN DEL DERECHO DEL CONSUMIDOR AL DERECHO PRIVADO COMÚN: SUS DIFICULTADES PRÁCTICAS. HACIA UN MODELO DE INTEGRACIÓN PARCIAL}

En el apartado anterior se estableció que desde un punto de vista teórico es posible argumentar en favor de un modelo de integración del derecho del consumo en el derecho común. Ahora bien, admitiendo que desde un punto de vista teórico o axiológico es posible la integración del derecho del consumo (o más bien parte de él) al derecho común, cabe todavía preguntarse si existen otras consideraciones que hagan sin embargo aconsejable el establecer o mantener una distinción entre ambas categorías. Es decir, el punto es determinar si es posible argumentar en favor de que se establezca una legislación separada en virtud de razones de política legislativa, no obstante que, tal como se dijo, teóricamente sea posible un modelo de integración.

Parecen haber razones prácticas que militan en contra de un modelo de integración total. En otras palabras, existen razones en virtud de las cuales parece adecuado sostener que debe existir un cuerpo orgánico y sistematizado que contenga y desarrolle las normas de protección al consumidor. Primero, permite a los usuarios un mejor acceso a la ley. Hay que recordar que las normas de protección al consumidor incluyen no solo normas de derecho privado, sino también de derecho público, ya sea procesales, administrativas e incluso penales. La propia naturaleza de las normas impide su inclusión completa en el CC, y refuerza la idea de una legislación separada. Segundo, una legislación separada parece ser también el lugar adecuado para incluir los derechos básicos o fundamentales de los consumidores, como el derecho a la información, a la educación, de asociación, etc., que no necesariamente son extensivos al derecho privado general ${ }^{23}$. Por último, la regulación de los contratos de consumo tiende a ser muy detallada y reglamentaria, ajena a la técnica de los CC. Así sucede por ejemplo con la normativa sobre contratos sobre tiempo compartido, viajes combinados o crédito al consumo.

La experiencia de los ordenamientos que han integrado de manera amplia el derecho del consumidor a sus CC sirve de ejemplo para confirmar las afirmaciones anteriores. Así, el CC holandés contempla la regulación del contrato de viaje combinado, pero la información que debe dar el proveedor al pasajero está contenida en una normativa reglamentaria especial, lo que hace difícil para el usuario el acceso a la ley. En Alemania, existen problemas de coherencia terminológica en el propio BGB, ya que la definición general de consumidor ( $\$ 13 \mathrm{BGB}$ ) no se ajusta la regulación que luego se hace, por ejemplo, de los contratos de viaje combinado y de servicio ${ }^{24}$.

De acuerdo a Micklitz, la integración del derecho del consumo al BGB ha sido exitosa solo en lo formal, principalmente porque el dinamismo del derecho del consumidor no puede adaptarse a la naturaleza estática del BGB. En este sentido, afirma que si las normas de derecho del consumo se integran al Código perderán vitalidad y dinamismo, por la naturaleza estática del Código, contrario a la naturaleza social de las normas de derecho

23 Joustra (1998) p. 136.

24 Micklitz (2013) p. 285. 
del consumo, lo cual ejemplifica con lo acontecido en Alemania, donde se han sucedido las actualizaciones a la normativa del consumidor después de la reforma del 2002 al BGB. Agrega que aun cuando formalmente se han integrado al BGB, las normas de derecho del consumo se siguen considerando especiales por la doctrina y la jurisprudencia, lo cual se refleja en su estatus secundario en los currículos de las facultades de derecho, y por su estudio particularizado y separado de las obras generales sobre el $\mathrm{BGB}^{25}$.

El reconocer la ventaja o necesidad de contar con un cuerpo orgánico (ley general o código) que reúna las normas sobre protección a los consumidores, no implica necesariamente sostener que dicho cuerpo deba ser exclusivo y excluyente, es decir, que contemple la totalidad de la normativa (a nivel legal al menos). Según paso a exponer, la mejor alternativa parece ser que las normas y principios básicos del derecho del consumidor (o más allá, de la protección y reconocimiento a la parte débil de la relación jurídica) se integren al CC, sin perjuicio que legislación especial las detalle y las desarrolle.

Este modelo de integración parcial tiene varias ventajas ${ }^{26}$ :

- El CC vuelve a recuperar su posición central en el sistema de derecho privado, incluyendo en su normativa relaciones jurídicas de relevancia contemporánea.

- Permite evitar o reducir las contradicciones (al menos a nivel de principios y reglas generales) entre el derecho del consumo y el derecho privado general

- Se produce una interacción en doble sentido entre el derecho común y el derecho del consumo. Por una parte, el derecho común se "moderniza", y por otra, el derecho del consumo no aparece como un derecho completamente excepcional, sino ligado también a las normas generales del derecho común, lo que le otorga legitimidad institucional. Así por ejemplo, el control de las cláusulas abusivas puede sustentarse como una aplicación del principio general de buena fe, y en particular, la exclusión o modificación de normas dispositivas solo es admisible si se justifica en base a la buena fe, es decir no produce resultados perniciosos para una de las partes. Así también, el derecho de retracto puede encontrar justificación como reflejo de situaciones de nulidad por vicios de error o dolo que se han objetivado ${ }^{27}$.

- Permite expandir el ámbito de aplicación de ciertas instituciones (p. ej. las cláusulas abusivas) a otros sujetos diversos del consumidor que también requieren protección por su situación de desventaja estructural.

- Permite que las normas de protección al consumidor sean interpretadas en base a principios reconocidos en el derecho común y no se consideren excepcionales, restringiendo su aplicación. El exceso de detalle en las normas sobre consumidores juega a veces en contra de una efectiva protección, ya que una interpretación excesivamente legalista no permite a los tribunales la suficiente flexibilidad para adecuar sus decisiones a nuevos supuestos. Sin embargo, la existencia de principios generales reconocidos en el derecho común, al que los jueces pudiesen remitirse, podría evitar

\footnotetext{
25 Micklitz (2013) pp. 284 y 285.

26 Refiriéndose en general a los argumentos favorables para integrar las principales normas del derecho del consumo al Código Civil, véase CÁmara Lapuente (2015).

27 VAlpuesta (2009) p. 414.
} 
dichos inconvenientes y permitir una aplicación de la normativa del consumo más acorde con su finalidad.

- Al subsistir la legislación especial de consumo, se mantiene la flexibilidad de la misma para adaptarse a cambios puntuales, sin afectar constantemente la estructura del CC.

La existencia de principios propios del derecho del consumidor ha sido expresamente reconocida en Chile por la Corte Suprema en el denominado caso Cencosud ${ }^{28}$. Antes, por cierto, la doctrina había hecho lo mismo. La integración de dichos principios en el CC permitiría que tal reconocimiento dejase de ser una cuestión doctrinal o jurisprudencial, o sujeta a los vaivenes propios de la legislación especial, ya que le otorgaría una calidad y estabilidad suficiente, una madurez, para desde el CC, poder desarrollarse por medio de la legislación particular.

En definitiva, la coexistencia de ambos regímenes bajo el paraguas del derecho civil es mutuamente beneficiosa. Permite a las reglas sobre contratos de consumo beneficiarse del desarrollo dogmático del derecho común, y por otra parte, permite que el derecho común no se quede anquilosado y responda de mejor manera a la realidad negocial actual ${ }^{29}$.

\section{MÁS ALLÁ DE LA PROTECCIÓN AL CONSUMIDOR}

La alternativa de integración que se plantea puede entenderse no simplemente como la integración parcial (esto es, de sus principios y normas generales) del derecho del consumo al derecho común, sino más bien como el desarrollo natural del derecho contractual contemporáneo. En este sentido, Hondius ha planteado la idea de la fuerza transformadora del derecho del consumo ${ }^{30}$. Desde una perspectiva inversa pero complementaria a la vez, en una reciente publicación se ha planteado en Chile que "hay que buscar una adecuada integración entre el sistema del derecho común con el de la Ley 19.496, de modo de que el derecho del consumo se pueda beneficiar de la larga experiencia acumulada por aquel" 31 .

No integrar las normas de derecho del consumo al código civil puede implicar desperdiciar reglas e instituciones que se han desarrollado en dicho ámbito y que por su naturaleza tienen la característica de poder generalizarse a otros supuestos. Un problema de no incorporar estos desarrollos al CC es que, aun cuando intrínsecamente tengan méritos para ser considerados una regla general aplicable a todo contrato, seguirán siendo considerados (en particular por la jurisprudencia) una excepción aplicable solo al régimen especial al cual pertenecen. Ello impide que ejerzan la influencia que merecerían sobre el derecho común. La regulación sobre cláusulas abusivas es un ejemplo claro de una institución cuya aplicación debiera generalizarse. En este sentido, Hesselink señala que no solo los consumidores merecen una legislación actualizada a los requerimientos económicos, sociales y tecnológicos de la sociedad contemporánea, sino también los demás contratantes, cualquiera que

28 SERNAC CON CENCOSUD (2013).

29 En este sentido, véase también Pinochet (2008), quien además sostiene que el Derecho del Consumo no configura una rama autónoma del derecho sino que forma parte del derecho civil

30 Hondius (2012) p. 171.

31 Baraona (2014) p. 402. 
ellos sean, incluyendo por cierto a empresarios y comerciantes. De otra forma, se produce una discriminación no justificada en la que no todos los sujetos que merecen protección la reciben $^{32}$.

La indiferencia del CC hacia el derecho del consumidor sugiere la idea que existe un derecho privado, o al menos general de contratos, de carácter superior o principal, junto al cual (o más bien, por debajo del cual) existe uno inferior o secundario, el derecho del consumidor, de carácter secundario y especial, interpretado por tanto restrictivamente ${ }^{33}$. De esta manera, la política legislativa que se adopte (distinción o integración) no es indiferente, ya que influye en la interacción y mutua influencia entre el derecho común y el derecho del consumidor. Así por ejemplo, en Chile el derecho del consumidor aún es en cierto sentido subestimado en relación con el CC; lo cual incluso se refleja en la normativa de la LPC, cuyo control (por regla general) está encargado a la jurisdicción de los Juzgados de Policía Local, cuyas decisiones solo son apelables, sin posibilidad que sean revisadas por la Corte Suprema vía recurso de casación ${ }^{34}$.

Así, se puede sostener que perfeccionar el Derecho común de contratos es, también, mejorar la protección de los consumidores ${ }^{35}$. Una regulación integral de las reglas de formación del consentimiento, comprendiendo las tratativas preliminares, de los vicios del consentimiento (incluyendo la influencia indebida y el abuso de posición dominante), de las cláusulas abusivas, un sistema de remedios coherente, etc.; evitaría contradicciones y la creación de distinciones, excepciones y contra excepciones muchas veces artificiales o que no responden a las actuales necesidades sociales o económicas.

Como se dijo, la tendencia es a ampliar el campo de aplicación de las normas protectoras a otros sujetos distintos del consumidor, pero que también se encuentran en una situación de desventaja estructural frente a su cocontratante (así sucede en la Directiva sobre derechos del consumidor, el DCFR, la CESL y en Chile con la ley 20.416 que fija normas especiales para las empresas de menor tamaño). Es por ello que se requieren normas de calidad y "legitimadas" por medio de su inclusión en el derecho general de contratos del CC.

Es artificial el forzar el concepto de consumidor para otorgar protección a partes que la merecen, pero que en estricto rigor no pueden considerarse consumidores. La Unión Europea (UE), ante la restricción del concepto de consumidor a las personas naturales, confirmada por la Corte de Justicia de la Unión Europea (CJUE), ha tenido que reconocer esta situación en normativa específica, ampliando la protección en materia de transporte, viajes combinados y servicios. En este sentido, Reich ha planteado que la protección de la parte débil puede ser considerar un principio general del derecho de la UE, manifestado principalmente por la protección a los trabajadores y a los consumidores, pero que se

\footnotetext{
32 Hesselink (2014) p. 34

33 Wilhelmsson (2007) p. 33.

34 El Proyecto de ley que modifica la LPC (Boletín No. 9.369-03), actualmente en tramitación, se hace cargo de esta cuestión, ya que elimina la competencia de los JPL para conocer de las causas sobre interés individual de los consumidores, entregando el conocimiento y resolución de la denuncia infraccional al SERNAC y las acciones indemnizatorias a la jurisdicción ordinaria civil.

35 Pasquau (2011) p. 507.
} 
está ampliando a otros sujetos como los usuarios de servicios públicos y eventualmente las PYMEs $^{36}$.

La necesidad de articulación se acentúa entonces por la dificultad de delimitar o restringir las normas de protección exclusivamente a los consumidores, ya que la realidad fuerza a reconocer que existen otros sujetos que merecen, en determinados supuestos, una protección similar a la concedida a los consumidores. El límite de protección se vuelve difuso, utilizándose por los tribunales o incluso el legislador (como sucede en la mencionada ley 20.416) instituciones nacidas y desarrolladas en el derecho del consumidor para proteger a "no consumidores".

De esta manera, la exclusividad de la noción de consumidor como parte débil a proteger en las relaciones de mercado, ha sido superada por la constatación que existen otras categorías de sujetos que se encuentran en una situación similar al consumidor y que por tanto merecen igual (o mayor) protección. Así sucede con las PYMEs, en particular con las denominadas micro y pequeñas empresas, y se ha ido reconociendo también respecto de los pacientes, pasajeros, clientes de servicios financieros, y otras categorías, sin importar si actúan como consumidores, como comerciantes, como representantes o miembros de una organización con o sin fines de lucro, o en otra calidad cualquiera.

Si entendemos que el Código Civil debe ser el derecho común o ley general del sistema de derecho privado, su normativa debe incluir la regulación general de aquellos contratos en que una de las partes se encuentre en una situación de desventaja o vulnerabilidad frente a la otra. Ello incluye no solo a los consumidores sino también a quienes se encuentren, en el caso particular, en una situación asimilable ${ }^{37}$.

Asimismo, los cambios y transformaciones del contexto socioeconómico y jurídico, acentuados durante las últimas décadas por el rápido avance de la tecnología y la globalización de las relaciones humanas y comerciales, han determinado que tanto la normativa común contenida en el Código Civil como la normativa especial se tornen insuficientes para responder a las necesidades de la sociedad contemporánea. Una de estas carencias es la falta de protección adecuada de la parte débil a través de una regulación general que vaya más allá de reacciones puntuales por medio de la dictación de normativa específica.

No se pretende que el derecho proteja a la parte negligente o displicente, sino evitar que proteja o deje sin sanción al que abusa de su posición. Se puede decir que no hay razones sustantivas para limitar la protección en materia contractual solo a los consumidores y no extenderla a otras partes que se encuentran en una situación de desventaja $\operatorname{similar}^{38}$. En este sentido, tal como se ha planteado por doctrina extranjera, hay que admitir que junto con los paradigmas de la libertad contractual y de la fuerza obligatoria del contrato, el derecho privado moderno reconoce el de la protección a la parte débil, manifestada particu-

\footnotetext{
36 ReICH (2014) pp. 56-57.

37 En relación con las normas de protección al consumidor, se ha señalado que "Por más específico que pueda resultar el ámbito objetivo de aplicación de algunas de las normas en cuestión, ellas, vistas en su conjunto, han introducido en el ordenamiento jurídico un nuevo núcleo de principios generales”; SIRENA (2006) p. 270.

38 Hesselink (2014) p. 35
} 
larmente, como ya se mencionó, en la persona de los arrendatarios, los consumidores y los pacientes, entre otros ${ }^{39}$.

Así, sería mejor establecer como principio el de la protección de la parte débil, entendida esta como aquella que se encuentra en una situación de desventaja estructural respecto de su contraparte, ya sea por motivos económicos, sociales o familiares. A ello debería agregarse la consagración positiva de una serie de instituciones que tienen como fin la sanción del abuso de la parte aventajada, esencialmente, deberes de información y cooperación pre y postcontractuales, protección frente a cláusulas abusivas, sanción al abuso del derecho y al abuso de posición dominante, y el reconocimiento de la excesiva onerosidad sobreviniente. Esto permitiría ofrecer protección a quienes efectivamente la requieren, y evitar injusticias y distorsiones que implican una interpretación restrictiva o amplia de la noción de consumidor, respectivamente. Así por ejemplo, la ley 20.416, al haber hecho aplicable la LPC a todos los actos y contratos celebrados entre una micro o pequeña empresa y sus proveedores, les ha otorgado protección en todo evento, aun cuando en el caso particular la micro o pequeña empresa sea la parte fuerte de la relación ${ }^{40}$. Por otra parte, los casos en que el consumidor material ha sido privado de la protección que ofrece la LPC, son ejemplos en el sentido contrario, donde una parte merecedora del amparo de la ley, no obtiene la protección que merece.

Siguiendo a Hesselink, el CC, en su calidad de derecho común, debiese en definitiva contemplar al ciudadano como sujeto a proteger ${ }^{41}$. Se requiere entonces que el CC considere la protección del ciudadano en su sentido amplio más que del consumidor en sentido estricto. Por ello no es deseable una separación total del derecho del consumidor del resto del derecho privado, ya que estigmatiza y limita a la persona dejando fuera otros elementos relevantes. La idea de un sistema de derecho del consumo, cerrado y aislado del resto del derecho privado, reduce la idea de persona a un mero consumidor o agente económico, olvidando el resto de roles y relaciones que dicha persona tiene en el ámbito del derecho privado.

Del mismo modo, tal como lo indica Micklitz, no hay diferencia conceptual entre una relación entre un proveedor y un consumidor y una entre proveedores o empresarios cuando una de las partes está en una situación de desventaja estructural (particularmente económica, en caso de las PYMEs) ${ }^{42}$. Por ello, se ha planteado que el énfasis debería ponerse en la posición de la persona en el mercado y no en el objeto o fin de la transacción que celebra, de manera de protegerse en términos amplios al "ciudadano pasivo de mercado" (passive market citizen), es decir, todo aquel que celebra un acto o contrato para satisfacer sus necesidades sin producir él mismo el servicio o producto objeto de la transacción ${ }^{43}$. Esta ampliación de protección de la parte débil más allá del concepto restringido de consumidor se ha producido en Europa (sin perjuicio de la noción restringida de consumidor

\footnotetext{
39 Hondius (2004) p. 246.

40 En este sentido, Momberg (2012) pp. 386-387.

41 Hesselink (2014) pp. 36 y 37.

42 Micklitz (2014) p. 288.

43 Reich y Micklitz (2014) p. 53.
} 
de la CJUE), p. ej. en el caso de la Directiva 2006/123/EC sobre servicios en el mercado interno en la cual se protege al destinatario de servicios (recipient of services), concepto que excede en mucho al de consumidor tradicional ${ }^{44}$. Lo mismo sucede en materia de turismo, protección de pasajeros y servicios financieros ${ }^{45}$. En definitiva, en general es el usuario no profesional el que adquiere protección, sin limitarla al consumidor ${ }^{46}$.

Tal como se señaló, se requiere formalmente una distinción entre el derecho del consumidor y el derecho privado general, manifestada en la existencia de legislación especial de consumo, pero solo luego de haber establecido en el CC normas generales y principios aplicables a todos los sujetos de derecho, sean estos consumidores, personas actuando exclusivamente en su ámbito privado, o comerciantes ${ }^{47}$. Por definición, el CC debe cubrir, al menos en su generalidad, todos los aspectos del derecho privado, estableciendo lo valores por los cuales se regirá el sistema. Esto requiere una reformulación de dichos valores y principios generales. En palabras de Hesselink: "No debería aceptarse -y por cierto no como una cuestión de dogma o resignación- que las normas generales y principios del derecho privado permanezcan anclados en el siglo XIX (o se retorne cada vez a ellos) mientras el derecho del consumo se mueve hacia adelante, en dirección al siglo XXI”48.

La configuración del criterio y de las normas (imperativas) aplicables a la protección de la parte débil debe necesariamente efectuarse desde y en la normativa común, es decir, formar parte integrante del CC. Ello se traduciría en que esta normativa común se aplicaría a todos aquellos casos (y exclusivamente en ellos) en que una de las partes se encuentre, según parámetros predeterminados por la misma ley, en una posición de desventaja frente a la otra, que requiera una compensación o remedio por parte del sistema jurídico para impedir el abuso de la contraparte del resto de la reglas legales (que han sido construidas bajo el supuesto de la igualdad entre las partes). Por cierto, este régimen común, si bien implica la introducción expresa de un nuevo principio a nuestro derecho civil, no debe suponer la derogación del principio de la libertad contractual, sino tan solo su morigeración y adaptación para aquellos casos en que se cumplan los supuestos para la protección de la parte débil ${ }^{49}$.

\footnotetext{
44 El art. 4 No. 3 de dicha Directiva define al destinatario de servicios como "cualquier persona física con la nacionalidad de un Estado miembro o que se beneficie de los derechos concedidos a estas por los actos comunitarios, o cualquier persona jurídica de las contempladas en el artículo 48 del Tratado y establecida en un Estado miembro, que utilice o desee utilizar un servicio con fines profesionales o de otro tipo".

45 Reich y Micklitz (2014) p. 53.

46 Reich y Micklitz (2014) pp. 54-60

47 Usando una terminología común en la literatura jurídica en idioma inglés, se trata de incluir tanto a las relaciones $\mathrm{B} 2 \mathrm{C}$ (business to consumer), $\mathrm{C} 2 \mathrm{C}$ (consumer to consumer) y $\mathrm{B} 2 \mathrm{~B}$ (business to business).

48 Hesselink (2014) p. 38.

49 Ello tampoco es incompatible, y al contrario, debe ser acompañado con la introducción de otras instituciones que atenúan el principio de la libertad contractual, como por ejemplo los deberes de cooperación, la sanción al abuso de posición dominante, la regulación de las cláusulas abusivas, el reconocimiento de la excesiva onerosidad sobrevenida y otras derivadas en general del principio de buena fe (que también requiere reconocimiento expreso y categórico en nuestra legislación común).
} 


\section{CONSIDERACIONES FINALES}

Parece evidente que la existencia de legislación de consumo ha modificado el panorama tradicional del derecho privado, no solo en tanto supone una legislación específica y excepcional, sino como una regulación general paralela a la civil y comercial en materia de contratos y daños, que se superpone, y de alguna manera deroga la normativa del Código Civil y del Código de Comercio ${ }^{50}$. En Chile ya se ha planteado que el derecho común positivo ha dejado de ser el marco de referencia para la regulación de la mayoría de las relaciones contractuales, ocupando su lugar la LPC. Así, se ha afirmado que la nueva normativa establecida en la ley $\mathrm{N}^{\circ} 20.416$ ha venido a afectar seriamente la vigencia efectiva del Código Civil como norma común del derecho de obligaciones y contratos chileno ${ }^{51}$.

Por otra parte, la expansión del concepto de consumidor y de la relación de consumo ha hecho que la LPC se aplique en muchas materias particulares, sometidas a normativa especial: servicios públicos o de utilidad pública, contratos bancarios, de transporte, de educación, de salud, etc. Puede incluso decirse que no existe ámbito de la economía o de la regulación que pueda entenderse excluido a priori de la LPC. Esto supone problemas interpretativos importantes, con conceptos y reglas que no se complementan sino más bien se superponen, o incluso se contradicen, con el inconveniente adicional que normas de naturaleza y finalidad opuesta pueden entenderse aplicables a la misma situación de hecho.

Si el Código Civil quiere mantener su rol como norma central y esencial del derecho privado, no puede ignorar en su estructura la regulación de aquellas relaciones jurídicas que han pasado a ser la regla general en la sociedad contemporánea; las cuales al mismo tiempo se beneficiarán de su pertenencia al Código, pudiendo "desplegarse en toda su potencialidad expansiva" hacia el resto del ordenamiento jurídico ${ }^{52}$.

Asimismo, como ha sostenido Zimmermann, reglas que pueden haberse planteado como aplicables a contratos de consumo no deben considerarse necesariamente como atentados a la libertad contractual, y por tanto, ajenas al sistema o a los valores del Código Civil. Al contrario, tales, reglas pueden considerarse como correcciones o esfuerzos para sostener la autonomía privada por medio de mecanismos que prevengan la conclusión o ejecución de contratos que no pueden considerarse el resultado legítimo de la voluntad de ambas partes ${ }^{53}$. Así por ejemplo, el desarrollo que el deber de información ha tenido en el derecho del consumidor, podría servir para determinar las normas generales que deberán aplicarse a toda relación contractual, particularmente cuando existan situaciones de desequilibrio informativo.

En este sentido, no se trata solo de insertar formalmente nuevas normas al Código, sino que debe efectuarse una integración orgánica en un sistema conceptual coherente, de modo que no se constituyan en meros elementos irritantes al sistema que finalmente terminen siendo ignorados en la práctica por abogados y tribunales.

\footnotetext{
50 Sobre la reforma indirecta de los códigos, véase VALLESPINOS y VARIZAT (2011) pp. 17-18.

51 Momberg (2012) pp. 388-389.

52 SirEna (2006) p. 271.

53 Zimmermann (2005) p. 210.
} 
En particular, en relación con el derecho del consumidor, lo planteado no implica que toda la normativa de protección al consumidor deba incorporarse al Código Civil, sino solo sus conceptos y principios fundamentales (por ejemplo, los conceptos de consumidor y proveedor, los deberes precontractuales de información, la normativa sobre cláusulas abusivas, el sistema de remedios en la contratación de consumo y los daños indemnizables) sin perjuicio que exista legislación especial de protección al consumidor en la cual dichos conceptos y principios fundamentales se concreten específicamente. En esta alternativa, la legislación común establecería una base mínima para la parte débil, sin perjuicio de la existencia de normativa especial para la protección de los consumidores. Lo mismo es aplicable para otros sujetos que requieran un estatuto protector, como por ejemplo, arrendatarios, pacientes o ciertas PYMEs.

El debate no es solo teórico, sino que tiene también importantes consecuencias prácticas: si se incorpora la protección de la parte débil como principio, ya sea explícitamente o a través de la integración de los diversos instituciones destinadas a proteger a la parte desventajada de la relación al CC, no cabría una interpretación restrictiva del mismo, sino al contrario, debería entenderse aplicable a todos los casos y para todas las partes que lo requieran, exista o no norma específica que así lo señale ${ }^{54}$.

Establecer un principio de protección a la parte débil, o al menos consagrar las instituciones básicas que cumplen dicho fin (como se ha dicho, entre otras, deberes precontractuales de información, regulación de las cláusulas abusivas y sanción al abuso de posición dominante) puede ser una estrategia exitosa para proteger efectivamente a quienes merecen protección, sin que se produzcan distorsiones o injusticias derivada de un concepto restringido de consumidor o de una aplicación restringida de la LPC.

En definitiva, de lo que se trata es de garantizar la justicia en el derecho privado, sin distinguir que en la relación jurídica intervenga o no un consumidor. La protección contra el abuso y la mala fe debe otorgarse a todas las partes, cualquiera sea su calidad. Como ya se ha dicho, la sanción de las cláusulas abusivas o al abuso de posición dominante no tiene por qué limitarse a las relaciones de consumo. El desafío es entonces llevar al derecho privado más allá del derecho del consumidor.

\section{BIBLIOGRAFÍA CITADA}

Albiez, Klaus (2003): "La integración del derecho de consumo contractual en el Código Civil: ¿Una simple entelequia o algo más?”, en CaBAnILLAS, Antonio (coord.), Estudios Juridicos en homenaje al profesor Luis Diez-Picazo, V.1 (Madrid, Civitas) pp. 139-152.

BARAONA, Jorge (2014): "La regulacion contenida en la ley 19.496 sobre protección de los derechos de los consumidores y las reglas del Código Civil y Comercial sobre contratos: un marco comparativo", Revista Chilena de Derecho, Vol. 41, № 2: pp. 381-408.

BarRientos, Francisca (2014): "La articulación de remedios en el sistema de la responsabilidad civil del consumo", Revista de Derecho de la Universidad Católica de Valparaíso, Vol. XLII: pp. 57-82.

54 Hondius (2014) p. 608. 
Camara Lapuente, Sergio (2015): "La codificación del derecho de consumo: ¿Refundación o refundición?”, Revista de Derecho Civil, Vol. II, No 1 (enero-marzo 2015). Disponible en http://nreg.es/ojs/index.php/RDC [visitado el 13/05/2015].

Caprile, Bruno (2008): "Las acciones del comprador insatisfecho: El cúmulo actual (Ley de protección al consumidor, vicios redhibitorios, error sustancial, resolución por incumplimiento) y la tendencia al deber de conformidad en el derecho comparado", en Mantilla, Fabricio y Pizarro, Carlos (coord.), Estudios de Derecho Privado en homenaje a Christian Larroumet (Santiago, Fundación Fernando Fueyo) pp. 561-602.

Hesselink, Martijn (2014): "Post-Private Law", Purnhagen, K. y Rott, P. (eds.), Varieties of European Economic Law and Regulation (Berlin y Londres, Springer) pp. 31-41.

Howells, Geraint y Weatherill, Stephen (2005): Consumer Protection Law (Aldershot, Ashgate).

Hondius, Ewoud (2004): "The Protection of the Weak Party in a Harmonised European Contract Law: A Synthesis", Journal of Consumer Policy, Vol. 27: pp. 245-251.

Hondius, Ewoud (2012): "The innovative nature of consumer law. Ius commune lecture 2010”, Journal of Consumer Policy, Vol. 35: pp. 165-173.

Hondius, Ewoud (2014): "Against a New Architecture of Consumer Law - A Traditional View”, en Purnhagen, K. y Rott, P. (eds.), Varieties of European Economic Law and Regulation (Berlin y Londres, Springer) pp. 599-610.

Joustra, Carla (1998): "Consumer Law", en Hartkamp, Arthur, Hesselink, Martijn, Hondius, Ewoud, Joustra, Carla y du Perron, Edgar (eds.), Towards a European Civil Code, 2 ed. (Nijmegen, Ars Aequi Libri) pp. 133-148.

Lima Marques, Claudia (2011): Contratos no Código de Defesa do Consumidor (São Paulo, Editora Revista dos Tribunais, sexta edición).

Micklitz, Hans-W. (2013): “Do Consumers and Business Need a New Architecture of Consumer Law? A Thought Provoking Impulse”, Yearbook of European Law, V. 32, N ${ }^{\circ}$ 1, pp. 266-367.

Momberg, Rodrigo (2012): "La transformación de la Ley de Protección de los Derechos de los Consumidores en la norma común del derecho de contratos chileno", en Elorriaga, Fabian (coord.), Estudios de Derecho Civil VII (Santiago, Thomson Reuters) pp. 377391.

Pasquau Liaño, Miguel (2011): "Protección de los consumidores y código civil: integración o distinción?”, en Albiez Dohrmann, Klaus Jochen (dir.), Palazón Garrido, María Luisa y Méndez Serrano, María del Mar (coord.), Derecho privado europeo y modernización del Derecho contractual en España (Barcelona, Atelier) pp. 485-508.

PInOChet, Ruperto (2008): "Integra el derecho de consumo el derecho civil, el derecho mercantil o conforma una disciplina jurídica autónoma?, en GuZMÁn Brito, Alejandro (ed.) Estudios de Derecho Civil III (Santiago, LegalPublishing) pp. 9-20.

ReICH, Norbert (2014): General Principles of EU Civil Law (Cambridge, Antwerp y Portland, Intersentia).

Reich, Norbert y Micklitz, Hans-W. (2014): "Economic Law, Consumer Interests, and EU Integration”, en Reich, Norbert, Micklitz, Hans-W., Rott, Peter y Tonner, Klaus 
(eds.), European Consumer Law (segunda edición, Cambridge, Antwerp, Portland, Intersentia) pp. 1-65.

Riefa, Christine (2015): “Codification: The Future of English Consumer Law?”, Journal of European Consumer and Market Law, V.1: pp. 12-20.

Sirena, Pietro (2006): "La integración del derecho de los consumidores al Código Civil", Revista de la Facultad de Derecho, Pontificia Universidad Católica del Perú, No. 58. Disponible en http://revistas.pucp.edu.pe/index.php/derechopucp/article/view/3090/2929 [visitado el 19/06/2014].

Vallespinos, Gustavo y Varizat, Andrés Federico (2011): "La integración de la ley de defensa del consumidor con los códigos civil y de comercio: problemas y propuestas de soluciones", en Vallespinos, Carlos (dir.) Cuaderno de Obligaciones No. 5. La ley de defensa del consumidor. Problemas y cuestiones controvertidas (Córdoba, Alveroni Ediciones) pp. 13-70.

VAlpuesta, Eduardo (2009): "El ámbito de regulación del futuro "derecho contractual europeo". De los principios sobre contratos comerciales a un derecho contractual general que incluya relaciones con consumidores", en Bosch CAPdevila, Esteve (dir.), Derecho contractual europeo. Problemática, propuestas y perspectivas (Barcelona, Bosch) pp. 405418.

Wilhelmsson, Thomas (2007): "Lex Mercatoria internacional y derecho del consumidor local. Una combinación posible?”, en Fernández Arroyo, Diego y Moreno RodríGueZ, José A. (eds.), Protección de los consumidores en Latinoamérica. Trabajos de la CIDIP VII (OEA) (Asunción, La Ley Paraguaya S.A., CEDEP) pp. 23-38.

Zimmermann, Reinhard (2005): The New German Law of Obligations: Historical and Comparative Perspectives (Oxford, Oxford University Press).

\section{NORMAS CITADAS}

Código Civil

Código de Comercio

Ley 19.496 sobre Protección de los Derechos de los Consumidores, 7 de marzo de 1997

Ley 20.416 que fija normas especiales para las empresas de menor tamaño, 3 de febrero de 2010

Ley 24.240 de Defensa del Consumidor (Argentina)

Ley 1.480 sobre Estatuto del Consumidor (Colombia)

Código de Defensa del Consumidor (Brasil)

Código de Protección y Defensa del Consumidor (Perú)

Código Civil y Comercial de la Nación Argentina

Consumer Protection Act 1987

Unfair Terms in Consumer Contracts Regulations 1999

Consumer Credit (Disclosure of Information) Regulations 2002

Consumer Right Act 2015

Código Civil Alemán - BGB

Código Civil Holandés - BW 
Code de la consommation (Francia)

Codice del consumo (Italia)

Texto refundido de la Ley General para la Defensa de los Consumidores y Usuarios y otras leyes complementarias (Real Decreto Legislativo 1/2007 - España)

Ley Federal de protección a los consumidores (Konsumentenschutzgesetz - Austria)

Ley de Defensa del Consumidor (Lei de Defesa do Consumidor, no 24/96, de 31 de julio Portugal)

Ley de Protección a los Consumidores (ley 2251/1994 - Grecia)

Directiva 2006/123/EC sobre servicios en el mercado interno

\section{JURISPRUDENCIA CITADA}

Sepúlveda y otros con Fuchs y Compañia Ltda (2007): Corte de Apelaciones de Concepción, 8 de noviembre de 2007, Rol No. 500-2005.

Ramirez con Viña del Mar Store (2008): Corte de Apelaciones de Valparaíso, 20 de febrero de 2008, Rol No. 1552-2007

Vásquez con Skartour Limitada (2008): Corte de Apelaciones de Punta Arenas, 23 de mayo de 2008, Rol No. 290-2007

Céspedes con Home Center (2008): Corte de Apelaciones de la Serena, 25 de julio de 2008, Rol No. 36-2008

SERNAC con CENCOSUD (2013): Corte Suprema, 24 de abril de 2013, Rol 12.355-1124. 